CZASOPISMO INŻYNIERII LA¿OWEJ, ŚRODOWISKA I ARCHITEKTURY JOURNAL OF CIVIL ENGINEERING, ENVIRONMENT AND ARCHITECTURE

JCEEA, t. XXXIII, z. 63 (1/I/16), styczeń-marzec 2016, s. 19-26

Lukasz KOSNO ${ }^{1}$

Łukasz SŁAWSKI ${ }^{2}$

Grzegorz ŚWIT ${ }^{3}$

\title{
EFEKTYWNOŚĆ BADAŃ GEORADAROWYCH PRZY OCENIE POPRAWNOŚCI WYKONANIA I STANU TECHNICZNEGO KONSTRUKCJI Z ELEMENTÓW PREFABRYKOWANYCH
}

\begin{abstract}
W Polsce elementy prefabrykowane są powszechnie stosowane w budownictwie ze względu na szereg zalet, spośród których najważniejszymi są niższe koszty wykonania, większa trwałość elementów czy skrócony czas realizacji obiektu. W chwili obecnej istnieje jednak potrzeba zastosowania nowoczesnych technik diagnostycznych ze względu na to, że niektórym konstrukcjom wybudowanym z elementów prefabrykowanych kończy się czas, na jaki zostały zaprojektowane, wprowadzono rozwiązania racjonalizatorskie polegające na zmianie średnicy, czy gatunku stali, zmianie położenia i rozmieszczenia zbrojenia, co powodują wzrost niepewności w kwestii bezpieczeństwa użytkowania tych budowli. W poniższym artykule zaprezentowano studium przypadku, w którym przedmiotem badań były prefabrykowane płyty warstwowe zastosowane w konstrukcji zewnętrznych ścian nośnych trzech budynków wykonanych z płyt prefabrykowanych systemu W-70. Elementy te zostały poddane badaniom ze względu na nieprawidłowości występujące $w$ trakcie przeprowadzanych prac termomodernizacyjnych. Do badań wykorzystano georadar, który pozwala na wykrywanie potencjalnych wad wewnątrz struktury badanego elemetu. W wyniku przeprowadzonych pomiarów otrzymano serię surowych radargramów, które następnie poddano obróbce przy pomocą specjalistycznego oprogramowania. Otrzymane przekroje radarowe umożliwiły zarówno określenie grubości warstw konstrukcyjnych badanych płyt, jak też zarejestrowanie oraz lokalizację anomalii mogących świadczyć o niewłaściwym wykonaniu elementów prefabrykowanych. Nieprawidłowości te mogą skutkować przedwczesną degradacją oraz awariami płyt warstwowych, a przez to doprowadzić do skrócenia okresu eksploatacji obiektu.
\end{abstract}

Słowa kluczowe: GPR, nieniszczące metody badawcze, elementy prefabrykowane, technologia wielkiej płyty

\footnotetext{
${ }^{1}$ Autor do korespondencji/ corresponding author: Łukasz Kosno, Politechnika Świętokrzyska w Kielcach, Wydział Budownictwa i Architektury, Katedra Wytrzymałości Materiałów, Konstrukcji Betonowych i Mostowych, Aleja Tysiąclecia Państwa Polskiego 7, 25-314 Kielce, 413424593, lkosno@tu.kielce.pl

${ }^{2}$ Łukasz Sławski, Politechnika Świętokrzyska w Kielcach, lukaslaw@poczta.fm

${ }^{3}$ Grzegorz Świt, Politechnika Świętokrzyska w Kielcach, gswit@tu.kielce.pl
} 


\section{Wprowadzenie}

Budynki z prefabrykatów wykonane w technologii wielkiej płyty są integralnym elementem krajobrazu polskich miast. Obecnie podlegają one rewitalizacji ze względu na zaawansowany wiek, współczesne wymagania ochrony cieplnej oraz oczekiwania co do poprawy walorów użytkowych i architektonicznych. Jednak podstawowym wymogiem determinującym zakres prac remontowych jest bezpieczeństwo użytkowania budynków. Przyjmuje się, że są one bezpieczne, o ile wykonano je zgodnie z projektem i założeniami technologicznymi. Jednakże stan techniczny wielu z nich wskazuje, że mogły one nie spełniać tych wymagań. Jest to szczególnie istotne z uwagi na wrażliwość budynków wykonanych z elementów prefabrykowanych na błędy produkcyjne i wykonawcze. Najbardziej narażone są systemy o wysokim stopniu gotowości, jak W-70 czy Wk-70 [1,2]. Lokalne uszkodzenia spowodowane tymi błędami najczęściej występują w złączach pionowych pomiędzy ścianami nośnymi oraz ścianami nośnymi i osłonowymi, w złączach poziomych (wieńcach), a także w połączeniu warstwy fakturowej i nośnej prefabrykowanych płyt ściennych, które realizowane jest przy pomocy stalowych wieszaków i szpilek. Uszkodzenia w złączach pomiędzy płytami występują najczęściej z powodu niewłaściwego wykonawstwa, a ich wpływ na bezpieczeństwo oraz sposoby ich napraw i wzmocnień opisano w licznych publikacjach. Natomiast uszkodzenia połączeń warstwy fakturowej i nośnej prefabrykatów są wadami "zakrytymi", przez co są trudne w identyfikacji, lecz nie są powiązane $\mathrm{z}$ uszkodzeniami $\mathrm{w}$ złączach i nie stanowią zagrożenia dla bezpieczeństwa konstrukcji budynku. Mogą one jednak stwarzać zagrożenie bezpieczeństwa użytkowania ze względu na możliwość uszkodzenia, a nawet odpadania warstwy fakturowej. Ponadto połączenia warstwy fakturowej i nośnej są elementem najbardziej narażonym na degradację i to one decydują o trwałości całego prefabrykatu [3]. Uszkodzenia połączeń pomiędzy warstwą fakturową i nośną prefabrykatu w większości spowodowane są błędami technologicznymi zakładu prefabrykacji. Do najczęściej występujących zaliczamy: brak efektywnego zakotwienia wieszaków w warstwach betonowych prefabrykatu, niewłaściwą ilość prętów kotwiących, ich średnicę lub rozmieszczenie, pochylenie wieszaków, zastosowanie niewłaściwej klasy stali, pęknięcia i korozję wieszaków, zaniżoną grubość otuliny czy nieprawidłowy montaż szpilek [1,2,3]. Identyfikacja uszkodzeń jest niemożliwa bez wykonania odkrywek. Pozwalają one jednak na ukazanie nieprawidłowości tylko w badanych miejscach, natomiast ocena bezpieczeństwa powinna dotyczyć każdego prefabrykatu, ponieważ obok elementu bez wad mogą znajdować się elementy uszkodzone. Wobec tego zasadne jest stosowanie nieniszczących metod badawczych, które również pozwalają rejestrować nieprawidłowości.

Celem artykułu jest wykazanie zasadności zastosowania metody georadarowej do badania elementów prefabrykowanych. Przedmiotem badań były trójwarstwowe płyty ścienne systemu W-70 zastosowane w konstrukcji ścian zewnętrznych trzech budynków - akademików Akademii Wychowania Fizycznego w War- 
szawie. Badania georadarowe zostały wykonane z powodu nieprawidłowości pojawiających się w trakcie przeprowadzanych prac ociepleniowych.

\section{Opis metody georadarowej i metodologia badań}

Metoda georadarowa, jest obecnie jedną z popularniejszych spośród nieniszczących metod badawczych. Opiera się ona na zjawisku odbicia fal elektromagnetycznych od granicy ośrodków, pomiędzy którymi występuje kontrast właściwości elektrycznych. Urządzenie emituje z nadajnika impuls elektromagnetyczny, który propaguje w głąb ośrodka. W momencie napotkania granicy ośrodków o zróżnicowanych wartościach stałej dielektrycznej jego część jest odbijana w kierunku nadajnika, a pozostała część propaguje w głąb, gdzie również może ulec odbiciu. Wartość współczynnika odbicia jest tym większa, im większy jest kontrast stałych dielektrycznych sąsiadujących ośrodków. Odbity sygnał trafia następnie do odbiornika i zostaje przetworzony na postać cyfrową z zadanym próbkowaniem. W ten sposób powstaje pojedynczy ślad radarowy, czyli A-skan. Złożenie A-skanów wzdłuż linii skanowania pozwala uzyskać B-skan, czyli profil podłużny badanego obiektu [4,5]. W celu umożliwienia jego wizualizacji, amplitudzie zarejestrowanego sygnału przypisane zostają kolory zgodnie z zadaną mapą. Następnie radargramy są poddawane obróbce przy pomocy specjalistycznego oprogramowania wykorzystującego odpowiednie procedury filtracyjne, co umożliwia poprawę stosunku sygnału użytecznego do szumu, korelacji i ciągłości refleksów użytecznych oraz minimalizację szumu losowego i eliminację zakłóceń zdeterminowanych [6]. Tak przetworzone profile można poddać interpretacji. Pamiętać należy jednak, że wykonanie pomiarów georadarowych, ich obróbka i interpretacja wymagają od użytkownika rozległej wiedzy obejmującej zagadnienia związane z elektromagnetyzmem, zasadą pracy georadaru oraz wiedzy inżynierskiej na temat badanego zagadnienia [7].

Przedstawione w artykule badania nieniszczące wykonane z zastosowaniem metody georadarowej, miały za zadanie sprawdzenie możliwości wykorzystania tej metody zlokalizowania i identyfikacji nieprawidłowości występujących w prefabrykowanych, trójwarstwowych elementach ściennych systemu W-70. Pomiary przeprowadzono przy użyciu georadaru typu RIS-K2 Alladin oraz anteny bipolarnej o częstotliwości $2 \mathrm{GHz}$. Zastosowano próbkowanie sygnału o wartości 1024, natomiast akwizycję prowadzono w oknie czasowym o długości 15 ns. Pomiary zastały wykonane w stałych interwałach odległościowych.

Dane georadarowe uzyskane dzięki obróbce zostały następnie poddane interpretacji, której wyniki przedstawiono w następnym rozdziale.

\section{Wyniki badań}

Metoda georadarowa pozwala na wgląd do wnętrza badanych prefabrykatów, co umożliwiło identyfikację elementów i warstw konstrukcyjnych. Prze- 


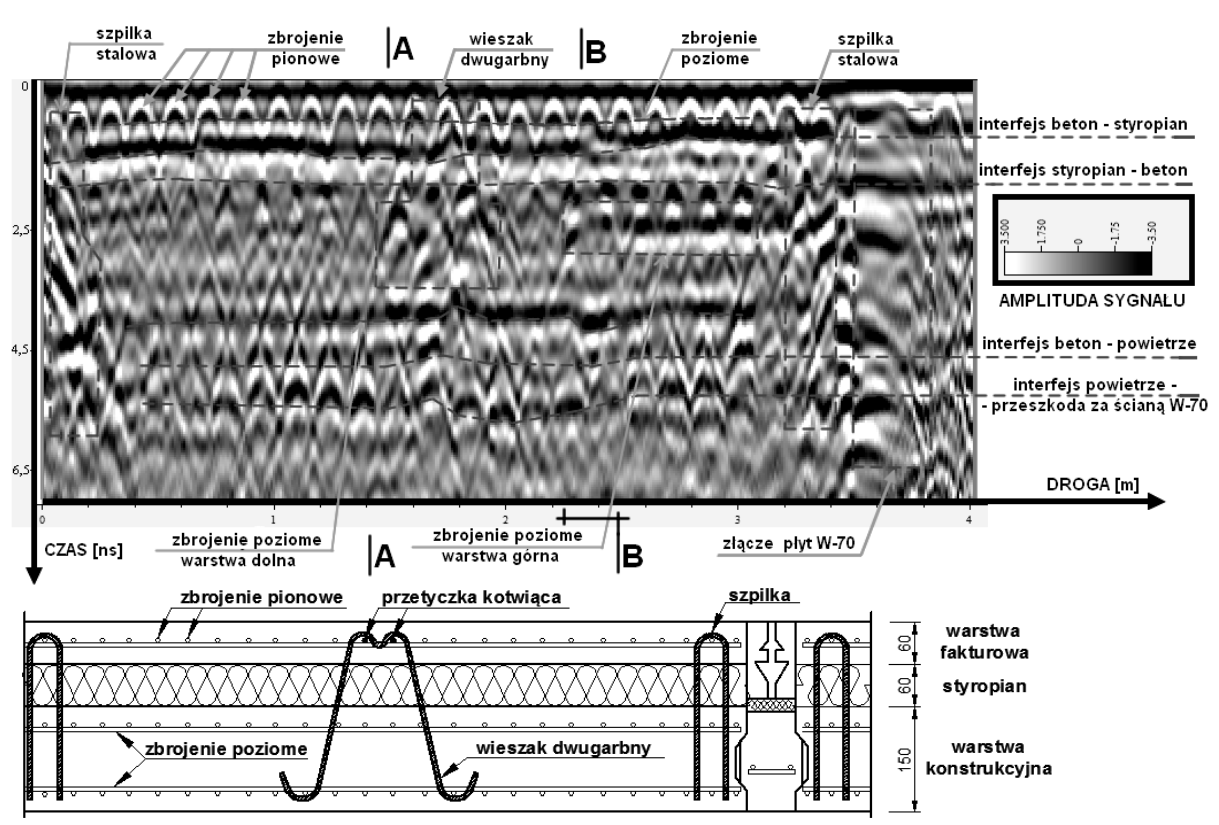

Rys. 1. Profil georadarowy płyty ściennej wraz z interpretacją

Fig. 1. Wall panel georadar profile and its interpretation

prowadzono analizę profili georadarowych (B-skanów) oraz pojedynczych śladów (A-skanów), a otrzymane wyniki porównano z dokumentacją techniczną. Przykładowy przekrój georadarowy z interpretacją przedstawiono na rysunku 1.

Powyższy profil przedstawia przekrój przez płytę ścienną systemu W-70. Widoczne są granice ośrodków beton-styropian (opóźnienie około 1ns), styropian-beton (opóźnienie około 2ns) i beton-powietrze (opóźnienie około 4,5ns). Ich krzywoliniowy charakter wynika z lokalnych zmian prędkości propagacji fali EM w ośrodku. Zróżnicowanie prędkości propagacji fali w warstwach betonu i izolacji powoduje również, iż proporcje grubości warstw widoczne na profilu nie pokrywają się z proporcjami rzeczywistymi. Wierzchołki widocznych na górze radargramu paraboli pokrywają się z lokalizacją prętów zbrojenia warstwy fakturowej, poprzecznych do kierunku skanowania. Widoczna jest również szpilka stalowa występująca po lewej stronie skanu, wieszak na jego środku oraz kolejna szpilka po stronie prawej. Zgodnie $\mathrm{z}$ dokumentacją techniczną systemu $\mathrm{W}-70$ zastosowano tu wieszak typu dwugarbnego. $\mathrm{Z}$ prawej strony radargramu zauważyć można anomalię wywołaną występowaniem elementów stalowych złącza płyt ściennych. Na części profilu po prawej stronie widoczne jest zbrojenie górne warstwy nośnej prefabrykatu. Opisany układ granic ośrodków został pokazany na śladach georadarowych oznaczonych jako A-A i B-B. W przypadku przejścia fali EM z ośrodka o niższej do ośrodka o wyższej prędkości propagacji fali, czyli na granicy beton-styropian i beton-powietrze ampli- 
tuda fali zmienia znak z minusa na plus. Analogicznie, w przypadku przejścia z ośrodka o wyższej do ośrodka o niższej prędkości propagacji fali, czyli na granicy powietrze-beton i styropian-beton amplituda fali zmienia znak z plusa na minus. Zmiana znaku amplitudy na granicy powietrze-beton (opóźnienie 0 do $0,2 \mathrm{~ns}$ ) nie jest wyraźnie widoczna ze względu na częściowe obcięcie wykresu fali przez procedurę filtracyjną przesuwająca skan do poziomu zero.
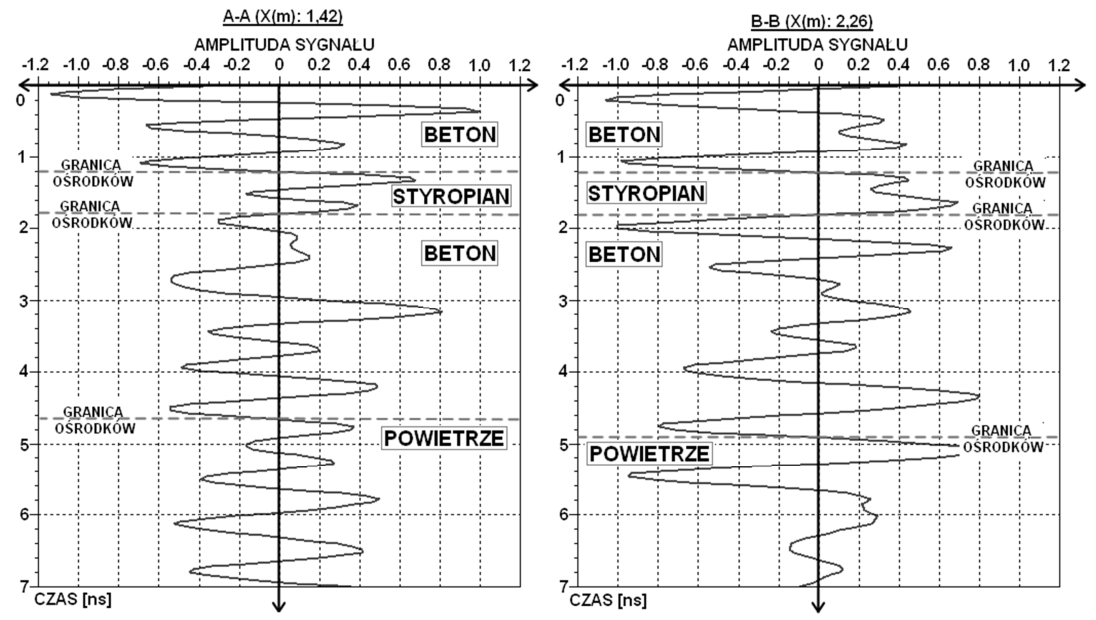

Rys. 2. Pojedynczy ślad georadarowy uzyskany w przekroju A-A $(x=1,42 \mathrm{~m})$ oraz $B-B(x=2,26 \mathrm{~m})$

Fig. 2. Single georadar trace obtained in cross-sectios $A-A(x=1.42 m)$ and $B-B(x=2.26 m)$

Poniżej przestawiono nieprawidłowości wykryte podczas badania prefabrykatów. Spośród najczęściej występujących typów uszkodzeń zarejestrowano: niewłaściwą ilość i rozmieszczenie wieszaków, brak efektywnego ich zakotwienia w warstwach betonowych, brak lub nieprawidłowe osadzenie szpilek. Wykryto również brak prętów zbrojenia warstwy fakturowej i zawilgocenie jej betonu. Metoda georadarowa pozwala też wykryć niewłaściwą grubość otuliny.

\subsection{Brak wieszaka}

Pierwszą z wykrytych wad jest brak wieszaka łączącego warstwę fakturową i nośną prefabrykatu. Jej wykrycie jest istotne, ponieważ zgodnie z projektem to wieszaki utrzymują ciężar warstwy fakturowej, przenoszą obciążenia wywołane ssaniem wiatru oraz zapewniają swobodę odkształceń warstw. W przypadku braku wieszaka część obciążenia może zostać przejęta przez sąsiedni wieszak lub szpilki, jednak może to spowodować przekroczenie nośności tych elementów. Należy zauważyć, że szpilki nie były zaprojektowane do przenoszenia takich obciążeń. Przedstawiony poniżej profil obrazuje obszar płyty, na którym stwierdzono brak wieszaka. Miejsce gdzie powinien się on znajdować zaznaczono czerwoną linią przerywaną. 


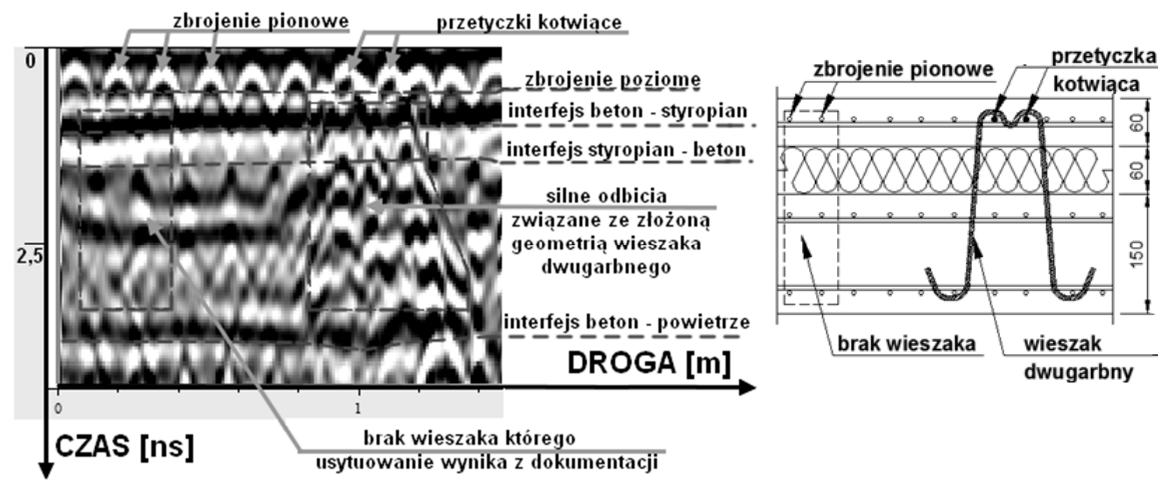

Rys. 3. Przekrój georadarowy obrazujący obszar płyty, w którym brakuje jednego z wieszaków

Fig. 3. Georadar cross-section illustrating area of panel where lack of hanger occurs

\subsection{Brak efektywnego zakotwienia wieszaka}

Kolejną wykrytą wadą było niewłaściwe zakotwienie wieszaka. Zgodnie z dokumentacją projektową przetyczka kotwiąca powinna obejmować pręty zbrojenia warstwy fakturowej od strony zewnętrznej. Jednak widoczne dwa wierzchołki parabol odpowiadające przetyczce występują poniżej wierzchołków parabol odpowiadających prętom zbrojenia warstwy fakturowej.

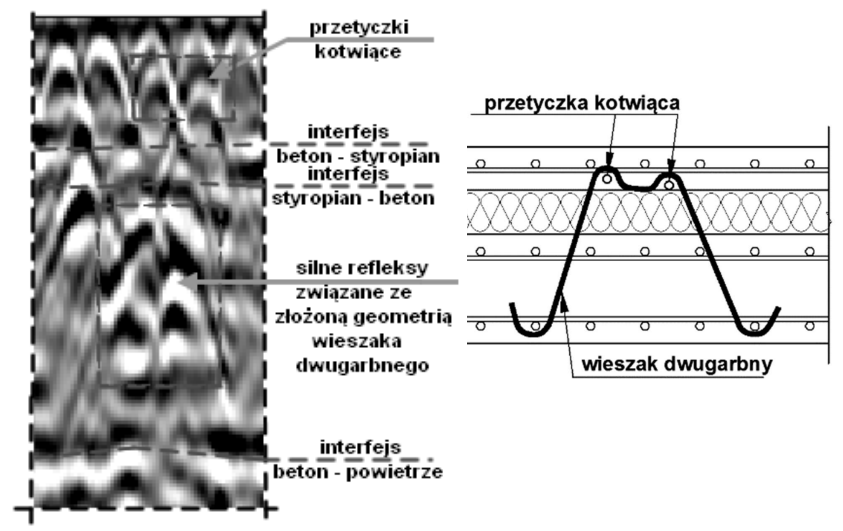

Rys. 4. Przekrój georadarowy przedstawiający niewłaściwie zakotwiony wieszak

Fig. 4. Georadar cross-section presenting improperly embedded hanger

\subsection{Brak prętów zbrojenia warstwy fakturowej}

Radargram uzyskany dla płyty z otworem okiennym ukazał kolejną nieprawidłowość. Jest nią brak pionowych prętów zbrojenia warstwy fakturowej ponad otworem okiennym. Wierzchołki parabol obrazujące pręty poprzeczne do kierunku skanowania (pionowe) występują tylko z lewej i prawej strony profilu. 


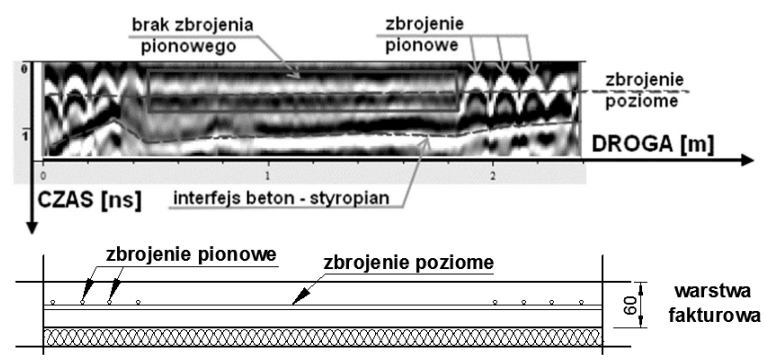

Rys. 5. Przekrój radarowy przedstawiający brak prętów zbrojeniowych nad otworem okiennym.

Fig. 5. Radar cross-section presenting lack of rebar above the window opening

\subsection{Zawilgocenie betonu warstwy fakturowej}

Radargram przedstawiony poniżej ukazuje kolejny typ zarejestrowanych nieprawidłowości, czyli zawilgocenie betonu warstwy fakturowej. Świadczy o tym widoczne zakrzywienie granicy ośrodków spowodowane spadkiem prędkości propagacji fali. Zjawisko to występuje tylko na skraju płyty, w pozostałej części profilu widoczne granice ośrodków mają właściwy przebieg. Anomalię tą można zauważyć również na śladach georadarowych przedstawionych poniżej.

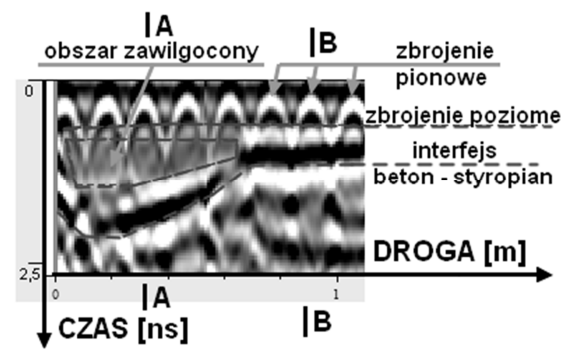

Rys. 6. Przekrój radarowy przedstawiający zawilgocenie warstwy fakturowej płyty

Fig. 6. Radar cross-section presenting presence of moisture in face layer of panel

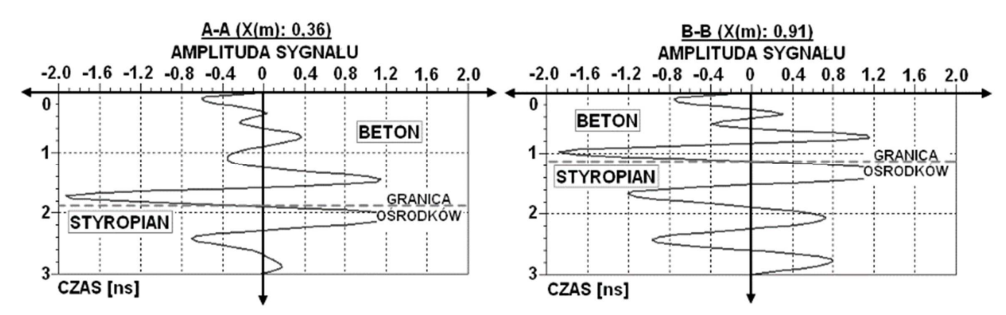

Rys. 7. Pojedynczy ślad georadarowy uzyskany w przekroju A-A ( $x=0,36 \mathrm{~m})$ oraz $B-B(x=0,91 \mathrm{~m})$

Fig. 7. Single georadar trace obtained in cross-sectios $A-A(x=0.36 m)$ and $B-B(x=0.91)$

\section{Wnioski}

W artykule wykazano, że metoda georadarowa jest efektywnym narzędziem pozwalającym na wgląd do wnętrza badanych obiektów. Ze względu na możliwość wykrycia szeregu wad może być pomocna w ocenie stanu technicznego 
oraz poprawności wykonania prefabrykatów. Dlatego przewiduje się coraz szersze jej zastosowanie w diagnostyce budynków prefabrykowanych.

\section{Literatura}

[1] Ligęza W.: Budownictwo wielkopłytowe po latach. Wybrane problemy remontowe, Budownictwo i Architektura, nr 13(3), 2014, s. 15-25.

[2] Dębowski J.: Analiza bezpieczeństwa zakotwienia warstwy fakturowej prefabrykatu wielkopłytowego po dociepleniu, Przegląd Budowlany nr 6, 2015, s. 12-17.

[3] Wójtowicz M.: Możliwość awarii warstwowych ścian zewnętrznych budynków wielkopłytowych - problem realny czy sensacja medialna, materiały konferencyjne, XXV Konferencja Naukowo-Techniczna, Międzyzdroje 24-27.05.2011, s. 533-542.

[4] Annan AP. Ground Penetrating Radar, Workshop Notes, Sensor \& Software, 2001.

[5] Lachowicz J., Rucka M.: Zastosowanie metody georadarowej w diagnostyce konstrukcji żelbetowych, Diagnostyka, vol. 16, nr 2, 2015, s. 31-36.

[6] Kosno Ł., Sławski Ł., Świt G.,: Inwentaryzacja niedostępnych elementów konstrukcji budynku z zastosowaniem georadaru na przykładzie budynku zabytkowego, monografia z 61. Konferencji Naukowej Bydgoszcz-Krynica, 20-25.09.2015

[7] Karczewski J.: Zarys metody georadarowej. Uczelniane wydawnictwo naukowo dydaktyczne AGH, Kraków, 2007.

\section{EFFICIENCY OF GEORADAR TESTING IN CONSTRUCTION CORRECTNESS AND TECHNICAL CONDITION ASSESSMENT OF STRUCTURES BUILT FROM PRAFABRICATED ELEMENTS}

\section{S u m m a r y}

In Poland prefabricated elements are in common use in civil engineering since 1970s. Significant number of structures was built with use of precast elements due to their advantages including lower cost of construction, higher sustainability and quicker construction process in comparison to traditional in-situ built construction members. Nowadays, due to execution incorrectness and advanced age of structures necessity of their technical condition control occurs more and more often. To assess condition of inaccessible layers and elements non-destructive testing methods should be used. One of the most popular NDT methods is Ground Penetrating Radar method. This paper presents a case study in which prefabricated sandwich panels comprising external supporting walls of three dormitory buildings of Physical Education Academy in Warsaw were investigated. These elements were examined in regard to incorrectness which occurred during thermo-modernisation works. As a result of the research series of raw radargrams were obtained and subsequently processed with dedicated software. Attained profiles allowed to determine layers' thickness of the investigated panels as well as to record and localise anomalies which could indicate the prefabricated elements' construction incorrectness. These improprieties could result in premature degradation and failure of prefabricated sandwich panels and lead to shortening lifespan of an object. Presented case study describes recorded construction incorrectnesses and their potential effects.

Keywords: GPR, non-destructive testing methods, prefabricated elements, large panel technology

Przestano do redakcji: 07.06.2016 $r$.

Przyjęto do druku: 30.06.2016 r.

DOI: $10.7862 / \mathrm{rb} .2016 .2$ 